\title{
EVALUASI PELAKSANAAN TUTORIAL TATAP MUKA PENDIDIKAN DASAR DI KABUPATEN SERAM BAGIAN BARAT PADA UPBJJ-UT AMBON
}

\author{
Wildoms Sahusilawane (wildoms@ut.ac.id) \\ Lilian Sarah Hiariey \\ UPBJJ-UT Ambon, Jl. Wolter Monginsidi Lateri, Ambon
}

\begin{abstract}
ABSTRAK
Artikel ini menyajikan hasil evaluasi pelaksanaan Tutorial Tatap Muka (TTM) di Kabupaten Seram Bagian Barat, Provinsi Maluku mengenai pelaksanaan dan faktor-faktor penghambat pelaksanaan TTM. Pengumpulan data di lapangan dilakukan dengan menggunakan teknik wawancara dan kuesioner. Data dianalisis secara deskriptif yaitu memberikan makna pada setiap data yang dikumpulkan, serta disajikan dalam bentuk persentase dan grafik. Hasil yang diperoleh menunjukkan bahwa pelaksanaan kegiatan TTM yang terdiri atas kegiatan awal, kegiatan inti dan kegiatan akhir terlaksana dengan baik sesuai dengan ketentuan yang ditetapkan oleh UT. Sedangkan faktor-faktor penghambat dalam pelaksanaan tutorial, adalah jarak, transportasi, sumber daya manusia (tutor), dan keterbatasan sarana komunikasi.
\end{abstract}

Kata kunci: evaluasi, pendidikan dasar, tutorial tatap muka

\begin{abstract}
This article presents the results of the evaluation of the implementation of Face to Face Tutorial in the District of West Seram, Maluku province on the implementation and the factors inhibiting the implementation of Face to Face Tutorial. Field data collection was done by using interviews and questionnaires. Data were analyzed descriptively that gives meaning to any data collected and presented in the form of percentages and graphs. The results obtained showed that the Face to Face Tutorial implementation consisting of initial activities, core activities and activities performing well late in accordance with the conditions set by the Open University. Meanwhile. inhibiting factors in the implementation of the tutorial, is the distance, transportation, human resources (tutors), and the limited means of communication.
\end{abstract}

Keywords: basic education, evaluation, face to face tutorial

Perkembangan jaman menuntut upaya peningkatan di setiap aspek tata kehidupan bangsa termasuk dunia pendidikan. Lebih khusus peningkatan Sumber Daya Manusia (SDM) pada guru Sekolah Dasar (SD) merupakan hal yang tidak dapat ditawar lagi. Demikian pula penyelenggaraan program S1 Pendidikan Guru Sekolah Dasar (PGSD) Universitas Terbuka (UT) yang bertujuan meningkatkan profesionalisme guru dalam menjalankan tugasnya.

Sejalan dengan itu, UT mengembangkan sistem jaminan kualitas (Simintas) sebagai upaya perbaikan dan peningkatan kualitas penyelenggaraan pendidikan jarak jauh secara menyeluruh, sistematis, dan berkelanjutan. Melalui Simintas, diharapkan pelaksanaan Program S1 PGSD-UT 
dapat terwujud dengan baik. Untuk itu, berbagai upaya perlu dilaksanakan di antaranya dengan mengadakan kegiatan evaluasi pelaksanaan program yang sedang berjalan. Kegiatan evaluasi ini secara khusus diharapkan dapat menggali kesulitan-kesulitan atau permasalahan penyelenggaraan Program S1 PGSD yang muncul di lapangan, serta sekaligus menemukan upaya pemecahan masalahnya. Hasil evaluasi ini diharapkan menjadi bahan masukan yang bermanfaat untuk pengembangan program selanjutnya.

Salah satu layanan yang disediakan oleh Universitas Terbuka dalam Program S1 PGSD adalah layanan bantuan belajar berupa Tutorial Tatap Muka (TTM), Tutorial melalui Radio, Televisi dan Media Massa, Tutorial Online (TUTON) dan Konseling Online.

Pelaksanaan program S1 PGSD di wilayah Unit Program Belajar Jarak Jauh (UPBJJ-UT) Ambon telah diupayakan berjalan sesuai ketentuan-ketentuan program, namun masih ditemukan beberapa kendala, keterbatasan-keterbatasan maupun kekurangan-kekurangan yang tidak dapat dihindari. Walaupun telah diantisipasi dalam rapat perencanaan, pembicaraan nonformal maupun tindakan langsung pada pelaku-pelaku terkait, ternyata masih saja dijumpai permasalahan dalam pelaksanaannya. Salah satu permasalahannya berkaitan dengan kondisi geografis wilayah TTM yang terdiri atas ratusan gugus pulau, mahasiswa baik para guru, pegawai negeri maupun masyarakat tersebar di ratusan pulau. Kondisi ini mempengaruhi operasionalisasi berbagai kegiatan UPBJJ- UT Ambon seperti pelaksanaan kegiatan tutorial.

Kabupaten Seram Bagian Barat adalah salah satu Kabupaten di UPBJJ-UT Ambon yang memiliki 4 (empat) kelompok belajar (Pokjar) dengan 248 mahasiswa program studi S1 PGSD dan S1 PGPAUD pada masa tutorial 2011.2. Berdasarkan informasi yang diperoleh dari pengurus kelompok belajar maupun keluhan mahasiswa yang disampaikan ke UPBJJ-UT Ambon, diketahui bahwa dalam pelaksanaan TTM yang dilakukan belum berjalan sesuai dengan ketentuan. Berbagai permasalahan atau kendala yang ditemui pada saat tutorial antara lain: jarak ke lokasi tutorial yang cukup jauh, sarana transportasi yang terbatas, terbatasnya sumber daya manusia (tutor) yang berada di daerah-daerah, serta sarana komunikasi yang belum memadai. Permasalahan TTM yang terjadi di Kabupaten Seram Bagian Barat ini, mendorong peneliti untuk melakukan penelitian tentang evaluasi pelaksanaan TTM Pendas di Kabupaten Seram Bagian Barat, UPBJJ-UT Ambon.

Secara umum evaluasi dapat diartikan sebagai upaya seksama untuk mengumpulkan, menyusun, mengelola dan menganalisis fakta, data dan informasi untuk menyimpulkan harga, nilai, kegunaan, kinerja dan lain-lain mengenai sesuatu (barang, hal, organisasi, pekerjaan, kegiatan dan lain-lain) yang kemudian dibuat kesimpulan sebagai proses bagi pengambilan keputusan.

Penelitian Evaluasi menurut Stufflebeam (1971) adalah sebagai suatu proses untuk mengungkap, mencari dan menganalisis serta menyajikan informasi untuk membuat keputusan. Sedangkan Levine (1981) menyatakan bahwa penelitian evaluasi adalah penelitian yang dilakukan untuk membeberkan hasil dari program. Kemudian hasil program tersebut dibandingkan dengan tujuan yang diharapkan.

Tutorial adalah program bantuan dan bimbingan belajar yang disediakan oleh UT yang bertujuan untuk memicu dan memacu proses belajar mandiri mahasiswa (Katalog UT, 2011). Tutorial adalah suatu proses pemberian bantuan dan bimbingan belajar dari seseorang kepada orang lain, baik secara perorangan maupun kelompok (pedoman tutorial S1 PGSD, 2005). Pihak yang membimbing disebut tutor, dan pihak yang disebut tutee.

Tutorial Tatap Muka (TTM) adalah salah satu bentuk layanan bantuan belajar yang ditandai dengan adanya pertemuan langsung secara tatap muka antara tutor dan mahasiswa. TTM wajib adalah layanan bantuan belajar dalam bentuk tutorial tatap muka yang sifatnya wajib disediakan 
oleh UT karena materi mata kuliah terkait dinilai sulit bila hanya dipelajari sendiri oleh mahasiswa. Nilai tutorial terdiri atas nilai tugas tutorial dan nilai partisipasi. Nilai tutorial akan memberi kontribusi $50 \%$ bagi nilai akhir (Pedoman Kualitas UT).

Untuk melaksanakan TTM yang efektif dan efisien, UT berpedoman pada Sistem Jaminan Kualitas (Simintas) JKOP-TR02 tentang perencanaan TTM. Tutorial ini dirancang secara khusus agar dapat membantu mahasiswa dalam menguasai kompetensi suatu mata kuliah.

Untuk memenuhi tututan tersebut UT telah mempersiapkan program untuk meningkatkan mutu tutorial yang dikenal dengan Program Akreditas Tutorial (PAT)-UT. Dengan panduan ini diharapkan tutor dapat melaksanakan tugasnya dengan baik. Apabila persyaratan tutor tersebut dilaksanakan dengan baik maka tutorial akan terlaksana dengan efektif. Disamping itu, tentu saja strategi belajar yang tepat oleh mahasiswa dalam menunjang efektifitas tutorial.

Tutorial adalah pemicu sekaligus pemacu proses belajar mahasiswa. Dari tutorial ini diharapkan para mahasiswa akan memiliki kemauan dan kemampuan untuk belajar, mengamati, berpikir, bersikap dan berbuat dalam mempelajari substansi mata kuliah dengan baik. Namun demikian, tutorial akan memberikan pengaruh yang besar terhadap keberhasilan belajar tutee bila tutor berperan sebagai fasilitator kegiatan belajar daripada sebagai pengajar.

Tujuan dari penulisan artikel ini adalah untuk (1) Memberikan gambaran pelaksanaan TTM di Kabupaten Seram Bagian Barat, (2) Mengetahui faktor-faktor penghambat pelaksanaan TTM Pendas di Kabupaten Seram Bagian Barat.

Sampel dalam penelitian ini adalah 23 mahasiswa menggunakan metode cluster sampling dimana semua anggota sampel diambil secara acak tanpa memperhatikan strata yang ada dalam anggota populasi. Persentase pengambilan sampel adalah $10 \%$ dari populasi jumlah mahasiswa pada masa registrasi 2011.2 yaitu sebanyak 238 mahasiswa dari program studi S1 PGSD, dan 15\% dari jumlah tutor yaitu 2 orang serta masing-masing pengurus pokjar yang berjumlah 3 orang. Metode yang digunakan dalam pengumpulan data adalah mengumpulkan data lapangan secara langsung ke lokasi tutorial dengan membagikan kuesioner dan melakukan wawancara dengan tutor dan pengurus kelompok belajar yang bermanfaat untuk kepentingan analisis yaitu dengan menggunakan teknik wawancara dan kuesioner. Teknik wawancara digunakan untuk mencari data mengenai proses pelaksanaan tutorial, sedangkan kuesioner digunakan untuk mencari data tentang proses perencanaan, pelaksanaan (inti) sampai dengan kegiatan penutup tutorial tatap muka

Teknik analisis data yang digunakan yaitu analisis deskriptif. Analisis deskriptif dilakukan dengan memberikan makna pada setiap data yang dikumpulkan dari hasil kuesioner dan wawancara maupun observasi, kemudian dianalisis dengan menggunakan metode persentase serta penyajian data dalam bentuk presentasi, dan diagram. Penarikan kesimpulan tentang masing-masing komponen dan indikator diambil berdasarkan kriteria yang telah ditentukan.

\section{HASIL PENELITIAN DAN EVALUASI Evaluasi Pelaksanaan TTM}

Untuk menilai dan mengevaluasi kegiatan tutorial tatap muka (TTM) ini, digunakan kuesioner yang disebarkan ke mahasiswa yang mengambil paket semester Program Pendidikan Dasar (Pendas) yang berada pada lokasi Kairatu, Piru dan Taniwel Kabupaten Seram Bagian Barat. Jumlah kuesioner yang disebarkan sebanyak 23 eksemplar dengan jumlah pertanyaan sebanyak 18 butir yang mencakup kegiatan tutorial dari kegiatan awal, kegiatan inti dan kegiatan akhir tutorial, Kemudian melakukan wawancara terhadap dua orang tutor dan pengurus pokjar tentang pelaksanaan tutorial tatap muka. Penelitian ini serupa dengan penelitian yang dilakukan oleh Triyono 
(2010) tentang Evaluasi Pelaksanaan Tutorial S1 PAUD FKIP-UT Semester 8 di Kabupaten Wonosobo.

Pelaksanaan tutorial tatap muka (TTM) di UPBJJ-UT Ambon telah dilaksanakan dengan baik dan berjalan sesuai dengan ketentuan yang ditetapkan oleh UT, dimulai dari proses perencanaan, pelaksanaan (inti) sampai dengan kegiatan penutup tutorial.

Pelaksanaan tutorial seperti tertulis dalam Bahan Ajar dari Tim Pengembang Program Akreditas Tutor (PAT)-Universitas Terbuka mempunyai tujuan (1) memberikan kesempatan kepada mahasiswa berinteraksi langsung dengan tutor dan mahasiswa lain, (2) membantu mahasiswa memecahkan masalah belajar, (3) memantapkan penguasaan materi, (4) meningkatkan motivasi dan percaya diri, (5) mengurangi rasa terisolasi atau kesepian dalam belajar. Adapun prinsip-prinsip tutorial hendaknya: (1) interaksi tutor dan tutee berlangsung pada tingkat kognitif tinggi, (2) tutor membimbing tutee lebih teliti, (3) tutor mendorong tutee sampai tahap pengertian, (4) tutor menghindari pemberian informasi semata, (5) tutor harus bisa mengembangkan diskusi, dan menghindari intervensi tutor selama diskusi berlangsung, (6) segala keputusan diambil melalui hasil berpikir kelompok, tutor harus yakin setiap tutee aktif dalam diskusi, (7) tutor mrnghindari interaksi khusus dengan tutee tertentu, (8) tutor perlu membuat variasi tutorial agar tutee tudak bosan, (9) tutor perlu memantau kemajuan belajar Tutee, (10) segala aktivitas tutorial merupakan kerjasama antara tutor dan tutee.

Adapun persyaratan keberhasilan tutorial menurut bahan Ajar dari Tim Pengembang PATUT sebagai berikut: (1) tujuan sebagai kriteria dan tolok ukur dalam menilai keberhasilan kegiatan tutorial secara keseluruhan, (2) proses kognitif yang akan dialami tutee misalnya melalui kajian kasus dan pemecahan masalah, (3) Proses belajar mandiri atau self-directed study guna menumbuhkan kemampuan belajar mandiri tutee.

Adapun jawaban yang diberikan mahasiswa pada kegiatan awal, kegiatan inti dan akhir tutorial adalah sebagai berikut:

1. Jawaban Terhadap Kegiatan Awal Tutorial

Tabel 1. Jawaban Mahasiswa Terhadap Pelaksanaan Kegiatan Awal Tutorial

\begin{tabular}{|c|c|c|c|c|c|}
\hline No Item & Pertanyaan & No & Jawaban & $f$ & $\%$ \\
\hline \multirow[t]{4}{*}{1} & Penjelasan Tujuan & 1 & Selalu menjelaskan & 12 & 52 \\
\hline & & 2 & Kadang-kadang menjelaskan & 6 & 26 \\
\hline & & 3 & Tidak pernah menjelaskan & 5 & 22 \\
\hline & & & Total & 23 & 100 \\
\hline \multirow[t]{4}{*}{2} & Menjelaskan Manfaat & 1 & Selalu menjelaskan & 17 & 74 \\
\hline & Tutorial & 2 & Kadang-kadang menjelaskan & 4 & 17 \\
\hline & & 3 & Tidak pernah menjelaskan & 2 & 9 \\
\hline & & & Total & 23 & 100 \\
\hline \multirow[t]{4}{*}{3} & Pertimbangan & 1 & Selalu mempertimbangkan & 16 & 70 \\
\hline & Permasalahan & 2 & Kadang-kadang mempertimbangkan & 4 & 17 \\
\hline & Tutorial & 3 & Tidak mempertimbangkan & 3 & 13 \\
\hline & & & Total & 23 & 100 \\
\hline \multirow[t]{4}{*}{4} & Penjelasan ruang & 1 & Sesuai & 18 & 78 \\
\hline & lingkup materi pada & 2 & Kurang sesuai & 3 & 13 \\
\hline & awal tutorial & 3 & Tidak sesuai & 2 & 9 \\
\hline & & & Total & 23 & 100 \\
\hline
\end{tabular}


Tabel 1. Lanjutan

\begin{tabular}{clclcc}
\hline No Item & Pertanyaan & No & Jawaban & f & $\%$ \\
\hline 5 & Pemberian motivasi & 1 & Ya & 13 & 56 \\
& oleh tutor & 2 & Kadang-kadang & 8 & 35 \\
& & 3 & Tidak pernah & 2 & 9 \\
\cline { 2 - 6 } & & & Total & $\mathbf{2 3}$ & $\mathbf{1 0 0}$
\end{tabular}

Sumber : data diolah, 2012

Dari Tabel 1 terlihat bahwa jawaban mahasiswa terhadap pelaksanaan kegiatan awal tutorial untuk setiap item pertanyaan yaitu tujuan, manfaat tutorial, pertimbangan permasalahan tutorial, ruang lingkup materi pada awal tutorial dan motivasi oleh tutor diperoleh hasil yang baik, yaitu antara 52\%-78\% responden menjawab baik. Hal ini menunjukan bahwa kegiatan awal tutorial yang diberikan oleh tutor sudah sesuai dengan materi tutorial yang diberikan. Hasil ini mendukung hasil penelitian yang dilakukan oleh Triyono (2010) yang menyatakan bahwa ruang lingkup yang dijelaskan oleh tutor sudah sesuai dengan materi tutorial.

2. Jawaban Terhadap Kegiatan Inti Tutorial Tabel 2. Jawaban Mahasiswa Terhadap Pelaksanaan Kegiatan Inti Tutorial

\begin{tabular}{|c|c|c|c|c|c|}
\hline $\begin{array}{l}\text { No } \\
\text { Item }\end{array}$ & Pertanyaan & No & Jawaban & $f$ & $\%$ \\
\hline \multirow[t]{4}{*}{6} & Penggunaan Metode & 1 & metode menarik & 12 & 53 \\
\hline & yang menarik & 2 & metode kurang menarik & 7 & 30 \\
\hline & & 3 & metode tidak menarik & 4 & 17 \\
\hline & & & Total & 23 & 100 \\
\hline \multirow[t]{4}{*}{7} & Penggunaan bahasa & 1 & sangat jelas & 19 & 83 \\
\hline & yang santun, jelas dan & 2 & cukup jelas & 3 & 13 \\
\hline & mudah dipahami & 3 & kurang jelas & 1 & 4 \\
\hline & & & Total & 23 & 100 \\
\hline \multirow[t]{4}{*}{8} & memberikan & 1 & selalu membimbing & 12 & 52 \\
\hline & bimbingan dan & 2 & kurang membimbing & 6 & 26 \\
\hline & pengarahan saat & 3 & tidak membimbing & 5 & 22 \\
\hline & diskusi & & Total & 23 & 100 \\
\hline \multirow[t]{4}{*}{9} & Memberikan motivasi & 1 & selalu memotivasi & 20 & 87 \\
\hline & saat diskusi & 2 & kadang-kadang & 3 & 13 \\
\hline & & 3 & tidak memotivasi & - & - \\
\hline & & & Total & 23 & 100 \\
\hline \multirow[t]{4}{*}{10} & Memberikan arahan atas & 1 & Ya & 17 & 74 \\
\hline & pertanyaan mahasiswa & 2 & kadang-kadang & 3 & 13 \\
\hline & & 3 & Tidak & 3 & 13 \\
\hline & & & Total & 23 & 100 \\
\hline \multirow[t]{4}{*}{11} & memberi umpan balik & 1 & Ya & 10 & 44 \\
\hline & atas hasil tugas & 2 & Kadang-kadang & 9 & 39 \\
\hline & mahasiswa & 3 & Tidak pernah & 4 & 17 \\
\hline & & & Total & 23 & 100 \\
\hline
\end{tabular}


Tabel 2. Lanjutan

\begin{tabular}{clrlcc}
\hline $\begin{array}{c}\text { No } \\
\text { Item }\end{array}$ & Pertanyaan & No & Jawaban & f & \% \\
\hline 12 & Penguasaan materi yang & 1 & sangat menguasai & 13 & 57 \\
& ditutorialkan oleh tutor & 2 & cukup menguasai & 7 & 30 \\
& & 3 & kurang menguasi & 3 & 13 \\
\cline { 2 - 6 } & & Total & $\mathbf{2 3}$ & $\mathbf{1 0 0}$ \\
\hline
\end{tabular}

Sumber : data diolah, 2012

Hasil jawaban terhadap kegiatan inti tutorial yang diberikan oleh mahasiswa pada tabel 2 menunjukan hasil yang baik, terutama untuk kegitan inti tutorial yaitu 44\%-87\%. Untuk jawaban terhadap pertanyaan mengenai memberikan motivasi saat diskusi memperlihatkan hampir seluruh mahasiswa memberikan jawaban bahwa tutor selalu memberikan motivasi saat pelaksanaan diskusi di kelas. Namun demikian, kurang dari separo responden, yaitu hanya 44\% responden yang menyatakan bahwa tutor selalu memberi umpan balik atas hasil tugas mahasiswa.

3. Jawaban Terhadap Kegiatan Akhir Tutorial Tabel 3. Jawaban Mahasiswa Terhadap Pelaksanaan Kegiatan Akhir Tutorial

\begin{tabular}{|c|c|c|c|c|c|}
\hline $\begin{array}{l}\text { No } \\
\text { Item }\end{array}$ & Pertanyaan & No & Jawaban & $\mathbf{F}$ & $\%$ \\
\hline \multirow[t]{4}{*}{13} & Memberi saran untuk & 1 & $\mathrm{Ya}$ & 12 & 52 \\
\hline & mempelajari modul di & 2 & Kadang-kadang & 5 & 22 \\
\hline & rumah & 3 & Tidak & 6 & 26 \\
\hline & & & Total & 23 & 100 \\
\hline \multirow[t]{4}{*}{14} & Menyimpulkan materi & 1 & Selalu menyimpulkan & 8 & 35 \\
\hline & tutorial & 2 & Kadang-kadang & 11 & 48 \\
\hline & & 3 & Tidak pernah & 4 & 17 \\
\hline & & & Total & 23 & 100 \\
\hline \multirow[t]{4}{*}{15} & Kesesuaian jadwal & 1 & Sesuai & 11 & 48 \\
\hline & tutorial & 2 & Kurang sesuai & 9 & 39 \\
\hline & & 3 & Tidak sesuai & 3 & 13 \\
\hline & & & Total & 23 & 100 \\
\hline \multirow[t]{4}{*}{16} & Kesesuaian tutorial & 1 & Sesuai & 17 & 74 \\
\hline & dengan tata cara & 2 & Kurang sesuai & 4 & 17 \\
\hline & tutorial & 3 & Tidak sesuai & 2 & 9 \\
\hline & & & Total & 23 & 100 \\
\hline \multirow[t]{4}{*}{17} & Tutorial dilaksanakan & 1 & Sesuai & 23 & 100 \\
\hline & sesuai dengan jadwal & 2 & Kurang sesuai & 0 & 0 \\
\hline & & 3 & Tidak sesuai & 0 & 0 \\
\hline & & & Total & 23 & 100 \\
\hline \multirow[t]{4}{*}{18} & Memberikan evaluasi & 1 & Memberikan evaluasi/tugas & 18 & 79 \\
\hline & secara tulisan atau & 2 & Kadang-kadang memberikan & 4 & 17 \\
\hline & tugas & 3 & Tidak pernah memberikan & 1 & 4 \\
\hline & & & Total & 23 & 100 \\
\hline
\end{tabular}


Hasil jawaban terhadap kegiatan akhir tutorial yang diberikan oleh mahasiswa pada Tabel 3 menunjukan hasil yang baik, yaitu 48\%-100\%. Hasil jawaban untuk pertanyaan mengenai tutorial dilaksanakan sesuai dengan jadwal, menunjukan seluruh mahasiswa menjawab bahwa tutorial dilaksanakan sesuai dengan jadwal yaitu 8x pertemuan.

Hasil jawaban dari ketiga tabel diperoleh jumlah jawaban terbanyak, dimana hasil ini dapat diketahui dari 18 butir pertanyaan yang dibagi dalam 3 bagian yaitu kegiatan awal tutorial (5 butir), kegiatan inti (7 butir) dan kegiatan akhir tutorial ( 6 butir). Dari hasil kuesioner tersebut dapat dihitung responden terbanyak untuk setiap masing-masing item. Dari data yang terkumpul, dapat diketahui kegiatan awal tutorial adalah 15 (100\%) dari nilai maksimal 15, sehingga dapat disimpulkan bahwa kegiatan awal tutorial menurut mahasiswa sudah sangat baik dengan nilai maksimal. Untuk kegiatan inti tutorial skor yang diperoleh adalah 18 (85,71\%) dari nilai maksimal 21. Menurut mahasiswa kegiatan inti sudah berjalan dengan baik. Sedangkan untuk kegiatan akhir tutorial adalah 17 (94,4\%) menurut mahasiswa sudah dilaksanakan dengan baik. Dari data yang terkumpul dapat disimpulkan bahwa untuk kegiatan awal, inti dan akhir tutorial sudah berjalan atau dilaksanakan dengan baik.

Hasil penelitian di atas untuk pelaksanaan tutorial Pendas di Kabupaten Seram Bagian Barat sejalan dengan penelitian yang dilakukan oleh Payman Triyono, dkk, bahwa pelaksanaan tutorial yang dilaksanakan di Kabupaten Wonosobo untuk mahasiswa S1 PAUD semester 8 telah dilaksanakan sesuai dengan aturan dan mekanisme pelaksanaan tutorial yang berlaku.

\section{Jawaban Pengurus Pokjar terhadap Pelaksanaan TTM}

Dari hasil wawancara dengan Pengurus Pokjar tentang pelaksanaan tutorial tatap muka khususnya tentang apakah pelaksanaan tutorial yang dilaksanakan sudah sesuai dengan jadwal yang ada. Jawaban yang diberikan oleh pengurus Pokjar adalah kegiatan tutorial sudah dilaksanakan sesuai dengan jadwal yang diberikan oleh UPBJJ-UT Ambon.

Jawaban Tutor terhadap pelaksanaan TTM

Hasil wawancara terhadap tutor diperoleh jawaban tentang pelaksanaan tutorial yaitu tutorial tatap muka sudah dilaksanakan dengan baik, dan kehadiran mahasiswa dalam mengikuti tutorial cukup tinggi. Adapun peran pungurus pokjar dalam kegiatan ini sangat didukung sehingga tutor yang hadir pada lokasi-lokasi tutorial dimulai dari kegiatan awal, inti dan akhir dapat berjalan sesuai dengan apa yang telah ditentukan dan direncanakan.

\section{Faktor-faktor Penghambat Pelaksanaan Kegiatan TTM}

Berdasarkan wawancara yang dilakukan dengan mahasiswa di lokasi TTM, terdapat beberapa faktor penghambat yang diperoleh, yaitu jarak, transportasi, keterbatasan sumber daya manusia, dan keterbatasan sarana komunikasi.

Dalam pelaksanaan kegiatan TTM Kabupaten Seram Bagian Barat, jarak jangkauan yang ditempuh mahasiswa maupun tutor cukup jauh dengan menempuh perjalanan kurang lebih 3-4 jam perjalanan dari tempat tinggal. Selain itupun sebelum waktu pelaksanaan TTM, mahasiswa sudah harus berada di lokasi tutorial sehari sebelum pelaksanaan tutorial berlangsung. Sehingga jarak menjadi salah satu faktor penghambat.

Keterbatasan sarana transportasi (angkutan umum) ke lokasi tutorial juga menjadi faktor penghambat. Mahasiswa harus menggunakan sarana transportasi alternatif lain yang membutuhkan biaya yang tinggi dalam mencapai tempat tutorial. 
Faktor penghambat lain yaitu kebutuhan kompetensi tutor di daerah yang terbatas, sehingga membutuhkan tenaga tambahan dari kota UPBJJ untuk membantu pelaksanaan TTM.

Keterbatasan komunikasi di daerah, karena minimnya jaringan telekomunikasi menyebabkan mahasiswa sering terlambat memperoleh informasi tentang waktu pelaksanaan tutorial di pusat kota. Hal ini juga merupakan faktor penghambat.

\section{PENUTUP}

Dari uraian di atas disimpulkan bahwa pelaksanaan Tutorial Tatap Muka (TTM) yang diselenggarakan di Kabupaten Seram Bagian Barat sudah dilaksanakan dengan baik sesuai dengan evaluasi dari mahasiswa, tutor dan pengurus pokjar. Meskipun demikian, terdapat faktor-faktor yang menghambat pelaksanaan tutorial tatap muka di Kabupaten Seram Bagian Barat yaitu, jarak, transportasi, sumber daya manusia (tutor), dan jaringan komunikasi.

Berdasarkan kesimpulan tersebut, beberapa saran diajukan untuk perbaikan, yaitu tutor dalam mempersiapkan pelaksanaan tutorial hendaknya memperhatikan petunjuk dan ketentuan yang disusun oleh tim pengembang PAT-UT. Kebutuhan kompetensi tutor di daerah terbatas, sehingga membutuhkan tenaga tambahan dari kota UPBJJ untuk membantu pelaksanaan TTM sehingga pelaksanaan tutorial dapat berjalan dengan baik. Pengurus pokjar lebih meningkatkan fungsi dan tugasnya dalam mengelola kelompok tutorial di daerah. Mahasiswa diharapkan lebih berperan aktif dalam kegiatan tutorial tatap muka khusunya diskusi-diskusi dan tugas-tugas yang dimulai sejak awal pertemuan sampai dengan selesai sehingga terlihat peningkatan aktivitas dalam tutorial. Keterbatasan sarana transportasi (angkutan umum) ke lokasi tutorial terbatas, sehingga mahasiswa menggunakan sarana transportasi alternatif lain yang membutuhkan biaya yang tinggi dan juga mahasiswa dapat mempersiapkan dirinya agar dapat ke lokasi tutorial lebih awal

\section{REFERENSI}

Arikunto Suharsimi. (2008). Dasar-dasar evaluasi pendidikan edisi revisi. Jakarta: Bumi Aksara.

Issac, S. \& Michael, William, B. (1984). Hand book in research and evaluation. San Diego: Edith Publisher.

Livine, Robert A. Et. Al. (1981). Evaluation research and practice. Beverly Hill; Sage Prodct.

Safuri, Musa (2005). Evaluasi program pembelajaran dan pemberdayaan masyarakat, Y-Pin Indonesia, Lembang Bandung.

Stufflebeam, Daniel L. (1971). Educational evaluation and desicioon making. Itaca Illionois: FE. Peacock.

Sukmadinata, N.S. (2009). Metode penelitian pendidikan. Bandung: PT. Remaja Rosda Karya.

Tim Pengembang PAT-UT. (2001). Bahan ajar program akreditasi tutor Universitas Terbuka, Jakarta: PAU-PPAI.

Tim UT. (2011). Katalog pendas tahun 2011, Jakarta, Universitas Terbuka.

Triyono P, dkk (2010), Evaluasi pelaksanaan tutorial S1 PAUD FKIP-UT semester 8 di kabupaten Wonosobo.

Tayipnapis, F.Y. (1989). Evaluasi program. Jakarta: Departemen Pendidikan dan Kebudayaan Direktorat Jendral Pendidikan Tinggi Proyek Pengembangan Lembaga Pendidikan Tenaga Kependidikan. , (2010). Pedoman kuliatas-layanan belajar jarak jauh UPBJJ-UT. , (2005). Pedoman tutorial S1 PGSD Universitas Terbuka, Jakarta. 